\title{
Exigência de lisina digestível para a tilápia-do-Nilo de 87 a 226 g alimentada com dietas balanceadas para a relação arginina:lisina
}

\section{Digestible lysine requirement of Nile tilapia from 86 to $227 \mathrm{~g}$ fed arginine to lysine balanced diets}

\author{
Wilson Massamitu Furuya ${ }^{1 *}$; Mariana Michelato ${ }^{2}$; Themis Sakaguti Graciano 3 ; \\ Luiz Vitor Oliveira Vidal'; Tadeu Orlandi Xavier²; \\ Valéria Rossetto Barriviera Furuya ${ }^{5}$; Lorena Batista de Moura ${ }^{6}$
}

\begin{abstract}
Resumo
Este estudo foi realizado com o objetivo de determinar a exigência de lisina digestível em dietas para alevinos de tilápia-do-Nilo de 87 a 226 g. Os peixes $(n=300$; peso inicial médio $=86,62 \pm 4,89 \mathrm{~g})$ foram distribuídos em 15 tanques-rede de $1000 \mathrm{~L}$, em delineamento inteiramente casualizado com cinco tratamentos e três repetições e alimentados com dietas extrusadas contendo 0,$88 ; 1,12 ; 1,36$; 1,59 e $1,83 \%$ de lisina digestível, balanceadas para relação arginina:lisina em 1,43:1. Pela análise Linear Response Plateau dos níveis de lisina sobre o ganho de peso diário, conversão alimentar, taxa de eficiência proteica e taxa de deposição de proteína, estimou-se exigência de 1,31;1,03;1,16 e 1,31\% de lisina digestível, respectivamente. Não foi observado efeito dos níveis de lisina na dieta sobre os teores de umidade e proteína corporal. Foi observado efeito quadrático dos níveis de lisina sobre a taxa de deposição de gordura e teor de extrato etéreo corporal, em que os menores valores dessas variáveis foram estimados com $1,16 \%$ e 1,43\% de lisina, respectivamente. Com o incremento nos teores de lisina na dieta ocorreu aumento linear no rendimento de filé e nível de proteína corporal. Concluiu-se que a tilápia-do-Nilo ( 87 a 226 g) exige 1,31\% de lisina digestível, em dietas balanceadas para a relação arginina:lisina.
\end{abstract}

Palavras-chave: Aminoácido, nutrição, peixes, deposição de proteína

\footnotetext{
Abstract

This study was conducted out to determine the dietary digestible lysine requirements of Nile tilapia from 87 to $226 \mathrm{~g}$. Fish $(\mathrm{n}=170$; average initial weight $=86.62 \pm 4.89 \mathrm{~g})$ were distributed $151000-\mathrm{L}$ cages, in a completely randomized design with five treatments and three replicates, and fed extruded diets containing $0.88 ; 1.12 ; 1.36 ; 1.59$ and $1.83 \%$ of digestible lysine, balanced to keep the arginine to lysine ratio as 1.43:1. There was no effect of the dietary lysine levels on whole body moisture and ash. By Linear Response Plateau analysis of lysine levels on daily gain, feed conversion, protein efficiency ratio and rate of protein deposition was estimated requirement of $1.31,1.03,1.16$ and $1.31 \%$ of lysine, respectively. A quadratic effect of lysine levels on whole body fat deposition ratio and whole body

${ }^{1}$ Prof. do Dept ${ }^{\circ}$ de Zootecnia, Universidade Estadual de Ponta Grossa, UEPG, Ponta Grosa, PR. E-mail: wmfuruya@uepg.br

${ }^{2}$ Discentes de Doutorado, Programa de Pós-graduação em Zootecnia, UEM, Maringá, PR. E-mail: marianamichelato@hotmail. com; tadeu_zoo@yahoo.com.br

${ }^{3}$ Pós-Doutoranda, Mestrado em Recursos Pesqueiros e Aquicultura, UNIOESTE, Toledo, PR. E-mail: the_graciano@yahoo.com.br

${ }^{4}$ Pós-Doutorando, Programa de Pós-Graduação em Zootecnia, UEM, Maringá, PR. E-mail: luizvitor.vidal@gmail.com

${ }^{5}$ Prof $^{\text {a }}$. do Dept ${ }^{\circ}$ de Zootecnia, UEPG, Ponta Grosa, PR. E-mail: vrbfuruya@uepg.br

${ }^{6}$ Discente de Mestrado, UEM, Maringá, PR. E-mail: lorenabatistamoura@gmail.com

${ }^{*}$ Autor para correspondência
} 
ether extract composition were observed, and the lowest values were estimated with $1.16 \%$ and $1.43 \%$ of dietary lysine, respectively. An increase of the dietary lysine levels resulted in linear increase on the fillet yield. The digestible lysine requirements of Nile tilapia (87 to $226 \mathrm{~g}$ ) is $1.31 \%$, in diets balanced for arginine to lysine ratio.

Key words: Amino acids, fish, nutrition, protein deposition

\section{Introdução}

A aquicultura é um dos setores da pecuária que mais cresce globalmente (FAO, 2010). Aproximadamente $40 \%$ do pescado cultivado no Brasil é originado da criação de tilápias, cuja produção nacional foi de 155.450,8 t em 2010 (MINISTÉRIO DA PESCA E AQUICULTURA, 2012).

Destacam-se os avanços nas áreas de melhoramento genético de tilápias no país, que têm contribuído para aumento na produção, principalmente em tanques-rede. Para permitir aos peixes expressar o potencial genético, é importante a contínua determinação das exigências nutricionais, considerando-se a diferentes linhagens e fases de desenvolvimento (FURUYA, 2010).

A lisina é um aminoácido essencial presente em elevada proporção no tecido muscular, envolvido no crescimento e manutenção do balanço nitrogenado positivo, utilizado também no "cross-linking" proteico, especialmente no colágeno. Além disso, é importante na síntese de carnitina, que atua no transporte de ácidos de cadeia longa (WALTON; COWEY, ADRON, 1984). A suplementação de lisina em dietas para peixes está relacionada com o aumento no ganho de peso, melhoria na conversão alimentar, aumento na retenção de nitrogênio e redução no conteúdo corporal de lipídios do salmão do Atlântico, Oncorhynchus mykiss (BERGE; SVEIER; LIED, 1998), tilápia-do-Nilo, Oreochromis niloticus (FURUYA et al., 2006) e Gilthead sea bream, Sparus aurata (MARCOULI et al., 2006).

Para alevinos de tilápia-do-Nilo, Santiago e Lovell (1988) estimaram exigência de 1,43\% de lisina na dieta. No Brasil, Bomfim et al.
(2010) determinaram exigência de $15,4 \%$ de lisina digestível para alevinos, valor próximo ao encontrado anteriormente por Furuya et al. (2006), que determinaram exigência de $14,3 \mathrm{~g} / \mathrm{kg}$ de lisina digestível para juvenis.

O efeito negativo do antagonismo da lisina sobre a utilização da arginina é amplamente conhecido (JONES, 1964; JONES; PETERSBURG; BURNETT, 1967), dada a importância da arginina na excreção de nitrogênio, especialmente em dietas com excesso de aminoácidos essenciais (SNETSINGER; SCOTT, 1961). Em condições práticas e experimentais, a suplementação isolada de lisina pode resultar em antagonismo com a arginina, pela alteração da relação entre os mesmos.

A recomendação da exigência dietética de lisina descrita anteriormente no NRC (1993) foi obtida com alevinos, enquanto que na nova edição do NRC (2011) foram apresentados dados obtidos com peixes de com, sendo poucas as informações sobre as exigências de lisina para peixes com peso médio de $100 \mathrm{~g}$. Ainda que diversos trabalhos tenham sido realizados com o objetivo de determinar as exigências de lisina para tilápias, poucas são as informações sobre as exigências de lisina digestível considerando a relação arginina:lisina.

Ainda que diversos trabalhos tenham sido realizados com o objetivo de determinar as exigências de lisina para diferentes espécies e fases de criação, poucas são as informações sobre as exigências de lisina digestível pelos peixes, principalmente considerando a relação arginina:lisina. O presente trabalho foi realizado com o objetivo de determinar a exigência de lisina digestível para a tilápia-doNilo de 87 a 226 g, alimentada com em dietas balanceadas para a relação arginina:lisina. 


\section{Material e Métodos}

O experimento foi realizado na Chácara ÁguaVerde, município de Guaíra, Paraná, no período de dezembro e janeiro de 2009, durante 45 dias. Foram utilizados 300 peixes $(86,62 \pm 4,89 \mathrm{~g})$, distribuídos em 15 tanques-rede de $1 \mathrm{~m}^{3}$, em delineamento inteiramente casualizado com cinco tratamentos e quatro repetições. Os tanques-rede foram acondicionados em um açude de $6000 \mathrm{~m}^{2}$, com água originada do rio Água-Verde, profundidade média de 2 metros e vazão de $10 \mathrm{~L} /$ segundo. No açude, não havia presença de outros peixes além dos alojados nos tanques-rede, sendo o experimento montado logo após a construção e abastecimento do mesmo.

Semanalmente, foram realizadas mensurado os dados de temperatura $\left({ }^{\circ} \mathrm{C}\right)$, oxigênio dissolvido (mg/L) e pH da água de cada tanque, duas vezes/ dia, as 8:30 e 17:00 h, por meio de oxímetro digital portátil (Hanna HI 9142, Hanna, São Paulo, SP, para oxigênio e temperatura) e pH-metro digital portátil (pH - TEC-3P-MP, Tecnal, Piracicaba, SP). Os dados foram mensurados no interior (centro) de cada tanque-rede, a uma profundidade de $20 \mathrm{~cm}$. Durante o período experimental foram obtidos valores de $28,3 \pm 1,66{ }^{\circ} \mathrm{C} ; 5,12 \pm 1,08 \mathrm{mg} / \mathrm{L}$ e 7,04 $\pm 0,12$, respectivamente, para temperatura, oxigênio dissolvido e $\mathrm{pH}$ da água dos tanques.

Os peixes foram alimentados com rações contendo $28 \%$ de proteína digestível e $3.454 \mathrm{kcal} /$ $\mathrm{kg}$ de energia digestível de forma a atender às exigências para tilápias (FURUYA et al., 2005; FURUYA, 2010) com 0,$88 ; 1,12 ; 1,36 ; 1,59$ e $1,83 \%$ de lisina digestível (base na matéria natural), sendo a arginina suplementada de forma a manter a relação arginina:lisina de 1,43:1 da dieta (Tabela 1).

As análises dos aminoácidos das dietas foram realizadas pela Ajinomoto do Brasil. As amostras para a composição corporal foram moídas em liquidificador, até obter-se uma amostra homogênea, que foi seca em estufa de ventilação forçada a $55^{\circ} \mathrm{C}$ por 72 horas e moída em moinho bola. As análises de matéria seca, proteína bruta, extrato etéreo, fibra bruta, cálcio e fósforo das dietas e umidade, proteína bruta, extrato etéreo e cinzas corporal foram realizadas no Laboratório de Nutrição Animal do Departamento de Zootecnia da Universidade Estadual de Maringá, seguindo-se metodologia descrita por Silva e Queiroz (2002).

Foram calculadas as taxas de deposição de proteína (TDP) e gordura corporal (TDG), conforme metodologia descrita por Fraga (2002). Para o cálculo da taxa de deposição de proteína corporal (TDP) foram coletados 30 peixes do lote inicial, comparados com os peixes que foram abatidos ao final do período experimental. A taxa de deposição de proteína corporal (g) foi calculada segundo a fórmula: $\mathrm{TDP}=\left(\mathrm{QP}_{\mathrm{cf}}-\mathrm{QP}_{\mathrm{ci}}\right) / \mathrm{PE}$, em que, $\mathrm{QP}_{\mathrm{cf}}$ é a quantidade, em gramas, de proteína na carcaça final; $\mathrm{QP}_{\mathrm{ci}}$ é a quantidade de proteína na carcaça inicial e PE é o período experimental, em dias. $\mathrm{QP}_{\mathrm{cf}}$ foi obtido multiplicando-se o peso da carcaça de um determinado indivíduo, ao final do experimento, pela respectiva proteína bruta da carcaça (PBC), enquanto $\mathrm{QP}_{\mathrm{ci}}$ foi obtido pelo peso do respectivo indivíduo, ao início do experimento, multiplicando pelo rendimento médio de carcaça e pela $\mathrm{PBC}$ média de seu grupo ao nascimento.

A taxa de deposição de gordura corporal (TDG) foi calculada segundo a equação: $\mathrm{TDG}=\left(\mathrm{QG}_{\mathrm{cf}}-\right.$ $\mathrm{QG}_{\mathrm{ci}} \mathrm{j} / \mathrm{PE}$, em que, $\mathrm{QG}_{\mathrm{cf}}$ é a quantidade, em gramas, de gordura na carcaça final; $\mathrm{QG}_{\mathrm{ci}}$ é a quantidade de gordura na carcaça inicial e PE é o período experimental, em dias. $\mathrm{QG}_{\mathrm{cf}}$ e $\mathrm{QP}_{\mathrm{ci}}$ foram obtidas de modo similar as $\mathrm{QP}_{\mathrm{cf}} \mathrm{e} \mathrm{QP}_{\mathrm{ci}}$, utilizando-se os valores de extrato etéreo da carcaça ao invés de proteína bruta da carcaça. A eficiência de retenção de proteína (ERP) foi calculada por meio da fórmula: ERP = TDP/CDL, em que, TDP é a taxa de deposição de proteína, em gramas e CDL é o consumo diário, em gramas (JAUNCEY; ROSS, 1982). O índice hepato somático (IHS) foi calculado segundo a equação: $\mathrm{IHS}=\mathrm{PFi} / \mathrm{PCx} 100$, sendo $\mathrm{PFI}=$ peso do fígado, $\mathrm{em}$ gramas e $\mathrm{PC}=$ peso corporal, em gramas. 
Tabela 1. Composição das dietas (\%) e composição calculada.

\begin{tabular}{|c|c|c|c|c|c|}
\hline & \multicolumn{5}{|c|}{ Lisina digestível (\%) } \\
\hline & $\mathbf{0 , 8 8}$ & 1,12 & 1,36 & 1,59 & 1,83 \\
\hline Milho, grão moído & 36,54 & 36,81 & 37,08 & 37,34 & 37,61 \\
\hline Carne e ossos, farinha 45 & 28,00 & 28,00 & 28,00 & 28,00 & 28,00 \\
\hline Milho, glúten 60 & 20,00 & 20,00 & 20,00 & 20,00 & 20,00 \\
\hline Sangue, farinha "spray-dried" & 4,00 & 4,00 & 4,00 & 4,00 & 4,00 \\
\hline Fosfato bicálcico & 0,50 & 0,50 & 0,50 & 0,50 & 0,50 \\
\hline Óleo de soja & 4,36 & 4,48 & 4,60 & 4,72 & 4,84 \\
\hline Ácido glutâmico & 2,00 & 1,50 & 1,00 & 0,50 & 0,00 \\
\hline L-alanina & 2,30 & 1,78 & 1,25 & 0,73 & 0,20 \\
\hline L-lisina & 0,00 & 0,30 & 0,60 & 0,90 & 1,20 \\
\hline L-arginina & 0,00 & 0,34 & 0,68 & 1,01 & 1,35 \\
\hline L-treonina & 0,30 & 0,30 & 0,30 & 0,30 & 0,30 \\
\hline DL-metionina & 0,23 & 0,23 & 0,23 & 0,23 & 0,23 \\
\hline Supl. mineral e vitamínico ${ }^{1}$ & 1,00 & 1,00 & 1,00 & 1,00 & 1,00 \\
\hline Vitamina $\mathrm{C}^{2}$ & 0,05 & 0,05 & 0,05 & 0,05 & 0,05 \\
\hline Antioxidante $^{3}$ & 0,02 & 0,02 & 0,02 & 0,02 & 0,02 \\
\hline Antifúngico 5 & 0,20 & 0,20 & 0,20 & 0,20 & 0,20 \\
\hline \multirow[t]{2}{*}{ Sal } & 0,50 & 0,50 & 0,50 & 0,50 & 0,50 \\
\hline & \multicolumn{5}{|c|}{ Composição calculada $^{5}$} \\
\hline Matéria seca (\%) & 90,35 & 90,31 & 90,27 & 90,22 & 90,18 \\
\hline Energia digestível (kcal/kg) & 3454,00 & 3454,00 & 3454,00 & 3454,00 & 3454,00 \\
\hline Proteína digestível (\%) & 28,00 & 28,00 & 28,00 & 28,00 & 28,00 \\
\hline Extrato etéreo (\%) & 8,60 & 8,72 & 8,85 & 8,97 & 9,09 \\
\hline Fibra bruta $(\%)$ & 1,15 & 1,16 & 1,17 & 1,18 & 1,19 \\
\hline Cálcio (\%) & 3,31 & 3,31 & 3,31 & 3,31 & 3,31 \\
\hline Fósforo disponível (\%) & 0,88 & 0,88 & 0,88 & 0,88 & 0,88 \\
\hline Metionina + cistina (\%) & 1,05 & 1,05 & 1,05 & 1,05 & 1,05 \\
\hline Lisina $(\%)$ & 0,88 & 1,12 & 1,36 & 1,59 & 1,83 \\
\hline Arginina (\%) & 1,26 & 1,60 & 1,94 & 2,28 & 2,62 \\
\hline Treonina (\%) & 1,02 & 1,02 & 1,02 & 1,02 & 1,02 \\
\hline Triptofano (\%) & 0,22 & 0,22 & 0,22 & 0,22 & 0,22 \\
\hline Arginina/lisina & 1,43 & 1,43 & 1,43 & 1,43 & 1,43 \\
\hline
\end{tabular}

${ }^{1}$ Suplemento mineral e vitamínico (Rovimix - DSM ${ }^{\circledR}$ ): composição por kg: Vit. A = 1.000 kUI; vit. D3 = 312 kUI; vit. E = 18.750 mg; vit. K3 = 1250 mg; vit. B1 = 2500 mg; vit. B2 = 2500 mg; vit. B6 = 1875 mg; vit. B12 = 3,75 mg; ác. fólico = 750 mg; ácido pantotênico $=6.250 \mathrm{mg}$; ácido nicotínico $=12.500 \mathrm{mg}$; vitamina $\mathrm{C}=31.250 \mathrm{mg}$; biotina $=125 \mathrm{mg}$; colina $=50.000 \mathrm{mg}$; cobre $=625 \mathrm{mg}$; ferro $=6250 \mathrm{mg}$; manganês $=1875 \mathrm{mg}$; cobalto $=12,5 \mathrm{mg}$; iodo $=62,5 \mathrm{mg}$; zinco $=6250 \mathrm{mg} ;$ selênio $=12,5 \mathrm{mg}$; inositol = $12.500 \mathrm{mg} ;{ }^{2}$ Vitamina C (Lutavit $\mathrm{C}($ ): sal cálcica 2-monofosfato de ácido ascórbico com (3500 mg de vitamina C/kg); ${ }^{3}$ Banox ${ }^{\circledR}$. Composição: BHA, BHT, galato de propila e carbonato de cálcio - Alltech do Brasil Agroindustrial Ltda. ; ${ }^{4}$ Mold Zap Aquativa ${ }^{\circledR}$. Composição: dipropionato de amônia, ácido acético, ácido sórbico e ácido benzóico - Alltech do Brasil Agroindustrial Ltda; ${ }^{5}$ De acordo com Furuya et al. (2001), Pezzato et al. (2002) e Guimarães et al. (2008a,b), com base em valores de aminoácidos digestíveis.

Fonte: Elaboração dos autores.

Os dados foram interpretados por meio de análise de variância a $5 \%$ de probabilidade. Os efeitos da lisina foram analisados por meio dos modelos de regressão linear, quadrático ou descontínuo "Linear
Response Plateau" (LRP), conforme o melhor ajustamento obtido para cada variável, com base na significância dos coeficientes de regressão pelo teste F, no coeficiente de determinação, na soma de 
quadrado dos desvios e no fenômeno em estudo. As análises estatísticas foram realizadas por intermédio do programa SAS (1988).

\section{Resultados e Discussão}

Não foi observado efeito $(\mathrm{P}>0,05)$ dos níveis de lisina na dieta sobre o índice hepatosomático e o rendimento de carcaça. Não foi observada mortalidade de peixes durante o período experimental. Pela análise Linear Response Plateau dos níveis de lisina sobre o ganho de peso diário, conversão alimentar, taxa de eficiência protéica e taxa de deposição de proteína, estimouse exigência de 1,$31 ; 1,03 ; 1,16$ e 1,31\% de lisina digestível, respectivamente. Foi observado efeito quadrático dos níveis de lisina sobre a taxa de deposição de gordura, em que a menor deposição de gordura corporal foi estimada com $1,16 \%$ de lisina (Tabela 2).

Tabela 2. Valores médios de desempenho de adultos de tilápia do Nilo em função alimentada com dietas com níveis crescentes de lisina digestível.

\begin{tabular}{|c|c|c|c|c|c|c|}
\hline \multirow{2}{*}{ Variável } & \multicolumn{5}{|c|}{ Lisina digestível (\%) } & \multirow{2}{*}{$\mathbf{C V}^{1}$} \\
\hline & $\mathbf{0 , 8 8}$ & 1,12 & 1,36 & 1,59 & 1,83 & \\
\hline Peso inicial (g) & 93,12 & 85,23 & 88,97 & 79,88 & 85,92 & 5,64 \\
\hline Peso final (g) & 211,19 & 227,17 & 227,20 & 228,63 & 236,42 & 4,06 \\
\hline Ganho de peso (g/peixe $)^{2}$ & 118,07 & 141,93 & 138,23 & 148,75 & 150,50 & 9,30 \\
\hline Conversão alimentar ${ }^{2}$ & 1,89 & 1,52 & 1,54 & 1,42 & 1,42 & 12,50 \\
\hline Taxa de eficiência protéica ${ }^{2}$ & 1,61 & 1,93 & 1,88 & 2,02 & 2,05 & 9,30 \\
\hline TDP $(\mathrm{mg} / \mathrm{dia})^{3}$ & 400,77 & 477,52 & 471,67 & 478,19 & 503,92 & 8,31 \\
\hline TDG $(\mathrm{mg} / \mathrm{dia})^{3}$ & 229,30 & 228,26 & 224,57 & 238,30 & 253,34 & 4,92 \\
\hline Índice hepatosomático & 6,72 & 6,38 & 6,25 & 5,81 & 6,25 & 12,23 \\
\hline Rendimento de carcaça (\%) & 88,24 & 88,04 & 88,25 & 88,51 & 88,47 & 0,22 \\
\hline Rendimento de filé $(\%)^{3}$ & 32,07 & 32,11 & 32,09 & 32,49 & 32,80 & 1,00 \\
\hline
\end{tabular}

${ }^{1}$ Coeficiente de variação; ${ }^{2}$ Linear response plateau $(\mathrm{P}<0,05)$ : ganho de peso: $\mathrm{y}=81,8644+45,1000 \mathrm{x}$; lisina $=1,31$; ganho de peso $=140,95 ; \mathrm{R}^{2}=0,85$; conversão alimentar: $\mathrm{y}=4,2399-2,6700 \mathrm{x}$; lisina $=1,03$; conversão alimentar $=1,49 ; \mathrm{R}^{2}=0,89 ;$ taxa de eficiência proteica: $\mathrm{y}=0,4162+1,3500 \mathrm{x}$; lisina $=1,16$; taxa de eficiência protéica $=1,98 ; \mathrm{R}^{2}=0,85$; taxa de deposição de proteína: $\mathrm{y}=287,8309+142,7700$; lisina $=1,31$; taxa de deposição de proteína $=474,39 ; \mathrm{R}^{2}=0,80 ;{ }^{3}$ Efeito quadrático $(\mathrm{P}<0,05)$ : taxa de deposição de gordura: $y=309,7-145,6 x+62,80 x^{2} ; \mathrm{R}^{2}=0,96 ;{ }^{4}$ Efeito linear $(\mathrm{P}<0,05)$ : rendimento de filé: $\mathrm{y}=31,26+0,774 \mathrm{x}$; $\mathrm{R}^{2}=0,80$.

Fonte: Elaboração dos autores.

No presente trabalho, o valor estimado de lisina para máximo ganho de peso, de 1,31\% de lisina digestível pelo modelo Linear Response Plateau (Figura 1) foi inferior ao descrito por Santiago e Lovell (1988), que estimaram exigência de $1,43 \%$ de lisina em dietas para a tilápia-do-Nilo na fase inicial. No entanto, quando a exigência é apresentada como porcentagem de lisina como parte da proteína, o valor determinado no presente trabalho $(4,67 \%)$ aproximou-se do valor $(5,1 \%$ da proteína da dieta) descrito por esses autores. Todavia, foi inferior aos valores obtidos por Murthy e Varghese (1997) e Fagbenro, Balogun e Fasakin (1998), de 2,24 (5,6\% da proteína) e $2,29 \%$ de lisina $(5,73 \%$ da proteína), com juvenis de carpa e bagre do canal, respectivamente, alimentados com dietas formuladas com base no valor de lisina total. 
Figura 1. Valores médios de desempenho de adultos de tilápia do Nilo alimentada com dietas com níveis crescentes de lisina digestível.

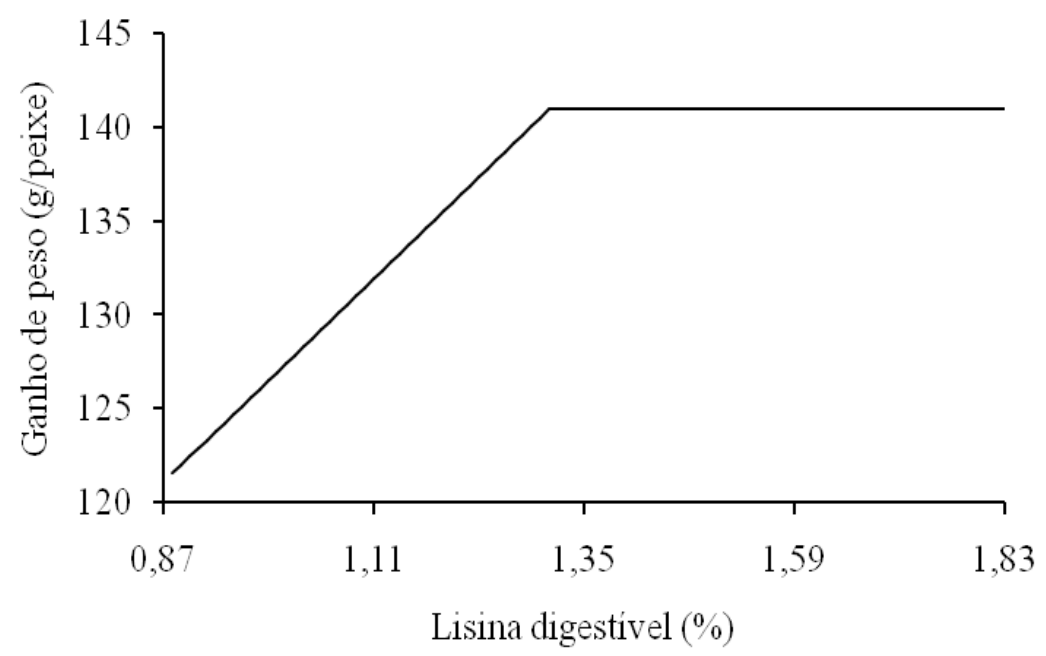

Fonte: Elaboração dos autores.

A baixa proporção de lisina em relação ao conteúdo de proteína da dieta é observada principalmente em dietas com valores elevados de proteína, como pode ser observado no trabalho realizado com juvenis de red sea bream por Forster e Ogata (1998), que estimaram valor de $1,73 \%$ de lisina $(3,3 \%$ da proteína) na dieta para máximo ganho de peso dos peixes alimentados com rações com $48 \%$ de proteína bruta. Isso foi demonstrado anteriormente por Tibaldi e Lanari (1991), que determinaram exigência de 2,17\% de lisina (4,34\% da proteína) para alevinos de Sea bass. Keembiyehetty e Gatlin III (1992) estimaram exigência de $1,41 \%$ de lisina (4,03\% da proteína) para juvenis de striped bass. Valores próximos foram obtidos por Berge, Sveier e Lied (1998), em juvenis de salmão do Atlântico, com valor de 1,8\% de lisina na dieta para máximo ganho de peso $(3,6 \%$ de lisina em relação à proteína bruta).

Assim, a comparação dos dados com base em valores de porcentagem da lisina da dieta ou como porcentagem da lisina em relação à proteína da dieta é subjetiva, se consideradas as diferenças nos níveis de proteína e a digestibilidade dos aminoácidos das dietas. Além disso, é importante ressaltar que, neste estudo, a proporção de lisina foi obtida com base nos valores de lisina e proteína digestíveis, enquanto os demais autores obtiveram essa relação com base em valores de lisina total e proteína bruta. Além disso, na maioria dos trabalhos as dietas foram realizadas sem a correção da proporção arginina:lisina.

No presente trabalho, os melhores valores de lisina para taxa de eficiência protéica $(1,16 \%)$ e taxa deposição de proteína (1,31\%) foram superiores aos descritos por Berge, Sveier e Lied (1998), para juvenis de salmão do Atlântico (1,6\% de lisina na dieta), divergindo também do valor descrito por Tibaldi e Lanari (1991), que determinaram exigência de $2,17 \%$ de lisina para juvenis de Sea bass $(0,85 \mathrm{~g})$ para máxima taxa de eficiência protéica. Diferem também dos resultados encontrados por Forster e Ogata (1998), que estimaram exigência de 2,16 e 2,11\% de lisina para alevinos de Flounder japonês e para o Red sea bream, respectivamente, para melhor taxa de eficiência proteica.

$\mathrm{O}$ aumento nos teores de lisina na dieta resultou em aumento linear $(\mathrm{P}<0,05)$ sobre o rendimento de filé. O filé é o principal produto resultante da industrialização de tilápias e o aumento no seu rendimento é importante para melhorar a resposta econômica da sua criação. No entanto, poucas são 
as informações sobre os efeitos da suplementação de lisina sobre o rendimento de filé de tilápias.

Apesar da impossibilidade de atribuir o maior rendimento de filé aos valores de lisina ou de arginina, considerando que ambas foram suplementadas para manter a relação arginina:lisina, ficou evidente que a suplementação de arginina influenciou a resposta sobre a exigência de lisina, uma vez que as exigências estimadas de lisina no presente trabalho são inferiores às obtidas anteriormente por Furuya et al. (2006), de 1,6\% de lisina digestível e Bomfim et al. (2010), de 1,7\% de lisina digestível.

Foi observado efeito quadrático $(\mathrm{P}<0,05)$ dos níveis de lisina nas dietas sobre a deposição de gordura, em que a menor deposição de gordura foi estimada com $1,16 \%$ de lisina (Figura 2). A menor deposição de gordura seguiu o comportamento inverso ao da deposição de proteína, demonstrando que a lisina é importante não somente para o crescimento do animal, mas também na deposição de proteína e redução nos teores de gordura corporal, como observado anteriormente por Berge, Sveier e Lied (1998) e Furuya et al. (2006). A redução corporal de lipídios nos peixes que receberam dieta suplementada com lisina pode ter ocorrido pelo fato da lisina atuar como um precursor da carnitina, que é envolvida no transporte de grupos acil dos ácidos de cadeia longa para a mitocôndria para a ß-oxidação (WALTON; COWEY; ADRON, 1984), ou ainda pelo aumento do conteúdo de proteína corporal per se, que resulta em menor proporção de gordura corporal.

Figura 2. Taxa de deposição de gordura (TDG) de adultos de tilápia do Nilo alimentada com dietas com níveis crescentes de lisina digestível.

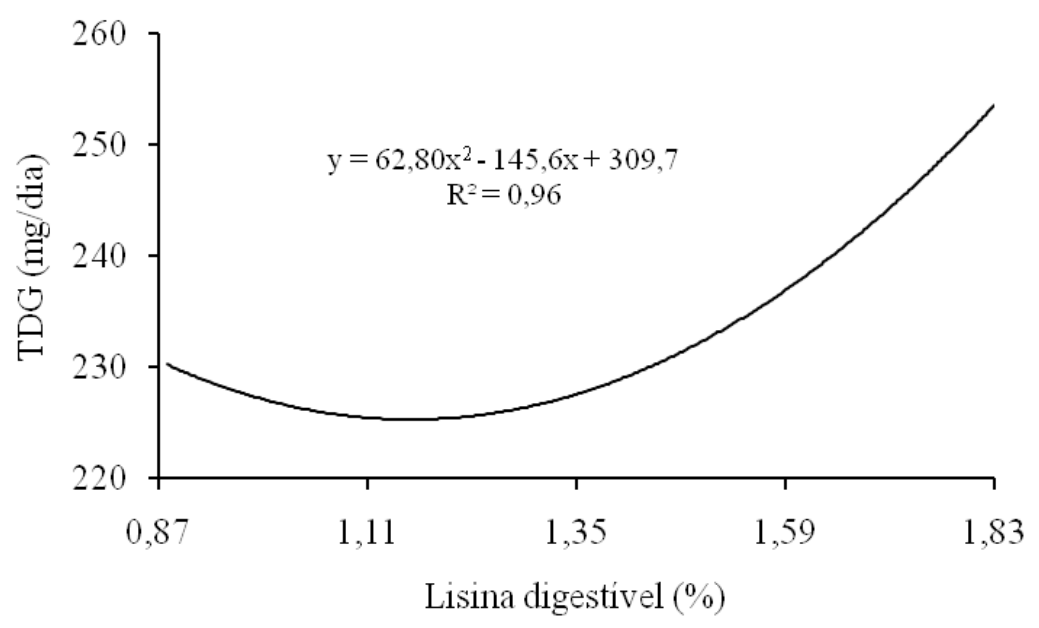

Fonte: Elaboração dos autores.

Não foi observado efeito $(\mathrm{P}>0,05)$ dos níveis de lisina sobre os teores de umidade e cinzas corporal. Pela análise dos dados pela Linear Response Plateau observou-se que a inclusão de lisina resultou em aumento linear nos teores de proteína corporal até atingir o nível de 1,24\% de lisina, não sendo observado aumento dessa variável a partir desse ponto. Foi observado efeito quadrático $(\mathrm{P}<0,01)$ dos níveis de lisina sobre os teores extrato etéreo na carcaça (Tabela 3), em que o menor valor de gordura na carcaça foi estimado com $1,43 \%$ de lisina digestível. 
Tabela 3. Valores médios de composição química da carcaça da tilápia do Nilo alimentada com dietas com níveis crescentes de lisina digestível.

\begin{tabular}{lrrrrrr}
\hline \multirow{2}{*}{ Variável (\%) } & \multicolumn{9}{c}{ Lisina digestível (\%) } & \multirow{2}{*}{ CV $^{\mathbf{1}}$} \\
\cline { 2 - 5 } & $\mathbf{0 , 8 8}$ & $\mathbf{1 , 1 2}$ & $\mathbf{1 , 3 6}$ & $\mathbf{1 , 5 9}$ & $\mathbf{1 , 8 3}$ & \\
\hline Umidade & 70,21 & 70,70 & 71,08 & 71,32 & 70,48 & 0,64 \\
Proteína bruta $^{(2)}$ & 18,00 & 18,24 & 18,33 & 18,29 & 18,24 & 1,22 \\
Extrato etéreo $^{(3)}$ & 9,16 & 8,28 & 8,29 & 8,35 & 8,61 & 4,37 \\
Matéria mineral $^{2}$ & 3,76 & 3,62 & 3,60 & 3,64 & 3,67 & 1,70 \\
\hline
\end{tabular}

${ }^{1}$ Coeficiente de variação; ${ }^{(2)}$ Linear response plateau $(\mathrm{P}<0,05)$ : proteína bruta: $\mathrm{y}=16,7242+1,260 \mathrm{x}$; lisina $=1,24$; proteína bruta $=$ 1,$24 ; \mathrm{R}^{2}=0,85 ;{ }^{(3)}$ Efeito quadrático $(\mathrm{P}<0,05)$ : extrato etéreo: $\mathrm{y}=14,23-8,468 \mathrm{x}+2,964 \mathrm{x}^{2} ; \mathrm{R}^{2}=0,89$.

Fonte: Elaboração dos autores.

Em estudo para avaliar a suplementação de L-lisina $\mathrm{HCl}(1,42 ; 2,14$ e 2,85\%) em dietas para alevinos de bagre do canal, Zarate e Lovell (1997) observaram aumento linear no conteúdo de proteína corporal. Comparando o desempenho de juvenis de truta arco-íris alimentados com rações contendo 0,89 e $1,96 \%$ de lisina, Rodehutscord et al. (2000) encontraram maior teor de proteína $(17,7 \%)$ na carcaça de peixes alimentados com dietas suplementadas com lisina. A menor deposição de gordura na carcaça com a suplementação de lisina, obtida neste estudo, concordam com os resultados obtidos por Davies, Morris e Baker (1997), Berge, Sveier e Lie. (1998) e Ahmed; e Khan (2004), com juvenis de truta arco-íris, salmão do Atlântico e carpa maior da Índia, respectivamente. De forma geral, observa-se grande variação nas exigências de lisina na dieta de peixes, de 3,2 a 8,8\% da proteína da dieta (TIBALDI; LANARI, 1991; KEEMBIYEHETTY; GATLIN III, 1992, WILSON, 1994; FORSTER; OGATA, 1998; HAULER; CARTER, 2001; ENCARNAÇÃO et al., 2004), com uma média de $5 \%$ para tilápias (NRC, 1993), valor recentemente atualizado para 5,3\% (NRC, 2011).

No presente trabalho, apesar da elevada suplementação de lisina nas dietas foi observado menor custo em ração $\mathrm{kg}^{-1}$ de peixe produzido e, considerando o maior rendimento de filés com o aumento dos níveis de lisina, viabiliza-se economicamente a inclusão de lisina em dietas para a espécie (Tabela 4). Apesar da importância da análise econômica em estudos de nutrição, ainda faltam informações sobre a resposta econômica da suplementação de aminoácidos em dietas para peixes.

Observou-se que a adequada relação entre os aminoácidos é importante para sua utilização da proteína, o que influencia o crescimento, a conversão alimentar, a deposição de proteína e gordura corporal, sendo possível viabilizar economicamente a suplementação de lisina quando são consideradas as respostas positivas sobre o rendimento de filé. A determinação da exigência de lisina para a tilápiado-Nilo é importante para permitir a elaboração de dietas com adequado balanceamento de aminoácidos, objetivando maximizar o crescimento, a eficiência de utilização da proteína, a composição corporal e aumento no rendimento de filé de forma economicamente viável.

\section{Conclusão}

Concluiu-se que adultos de tilápia-do-Nilo de 87 a 226 g exigem suplementação de 1,31\% lisina digestível na dieta.

\section{Agradecimentos}

Aos agricultores Vitório Saburo Furuya e Victor Ander Furuya, os autores agradecem pela contribuição na montagem, coleta de dados e manejo dos peixes durante o experimento. 


\section{Referências}

AHMED, I.; KHAN, M. A. Dietary lysine requirement of fingerling Indian major carp, Cirrhinus mrigala (Hamilton). Aquaculture, Amsterdam, v. 235, n. 1-4, p. 499-511, 2004.

BERGE, G. E.; SVEIER, H.; LIED, E. Nutrition of Atlantic salmon (Salmo salar); the requirement and metabolic effect of lysine. Comparative Biochemistry and Physiology, New York, v. 120a, n. 3, p. 477-485, 1998.

BOMFIM, M. A. D.; LANNA, E. A. T.; DONZELE, J. L.; QUADROS, M.; RIBEIRO, F. B.; SOUSA, M. P. Níveis de lisina, com base no conceito de proteína ideal, em rações para alevinos de tilápia-do-nilo. Revista Brasileira de Zootecnia, Viçosa, v. 39, n. 1, p. 1-8, 2010.

DAVIES, S. J.; MORRIS, P. C.; BAKER, R. T. Partial substitution of fish meal and full-fat soya bean meal with wheat gluten and influence of lysine supplementation in diets for rainbow trout, Oncorhynchus mykiss (Walbaum). Aquaculture Research, Oxford, v. 28, n. 5, p. 317-328, 1997.

ENCARNAÇÃO, P.; DE LANGE, C.; RODEHUSTCORD, M.; HOEHLER, D.; BUREAU, W.; BUREAU, D. P. Diet digestible energy content affects lysine utilization, but not dietary lysine requirements of rainbow trout (Oncorhynchus mykiss), for maximum growth. Aquaculture, Amsterdam, v. 235, n. 1-4, p. 569586, 2004.

FAGBENRO, O. A.; BALOGUN, A. M.; FASAKIN, E. A. Dietary lysine requirement of the African catfish, Clarias gariepinus. Journal of Applied Aquaculture, Philadelphia, v. 8, n. 2, p. 71-77, 1998.

FOOD AND AGRICULTURAL ORGANIZATION FAO. The state of world fisheries and aquacultgure 2010. Rome: FAO, 2010.

FORSTER, I.; OGATA, Y. Lysine requirement of juvenile Japanese flounder Paralichthys olivaceus and juvenile red sea bream Pagrus major. Aquaculture, Amsterdam, v. 161, n. 1-4, p. 131-142, 1998.

FRAGA, A. L. Exigência de lisina para suínos em fase inicial (15-30 kg), de dois grupos genéticos, em rações formuladas de acordo com o conceito de proteina ideal. Maringá: Universidade Estadual de Maringá, 2002.

FURUYA, W. M. Tabelas brasileiras para a nutrição de tilápias. Toledo: GFM, 2010.

FURUYA, W. M.; BOTARO, D.; SANTOS, V. G.; SILVA, L. C. R.; SILVA, T. S. C.; FURUYA, V. R. B.; SAKAGUTI, E. S. Exigência de lisina digestível para juvenis de tilápia do Nilo (Oreochromis niloticus).
Revista Brasileira de Zootecnia, Viçosa, v. 34, n. 6, p. 1933-1937, 2006.

FURUYA, W. M.; PEZZATO, L. E.; PEZZATO, A. C.; BARROS, M. M.; MIRANDA, E. C. Coeficientes de digestibilidade e valores de aminoácidos digestíveis de alguns ingredientes pela tilápia do Nilo (Oreochromis niloticus). Revista Brasileira de Zootecnia, Viçosa, v. 30, n. 4, p. 1125-1131, 2001.

FURUYA, W. M.; BOTARO, D.; MACEDO, R. M. G.; SANTOS, V. B.; SILVA, L. C. R.; SILVA, T. S. C.; FURUYA, V. R. B.; SALES, P. J. P. Aplicação do conceito de proteína ideal para redução dos níveis de proteína em dietas para tilápia-do-nilo (Oreochromis niloticus). Revista Brasileira de Zootecnia, Viçosa, v. 34, n. 5, p. 1433-1441, 2005.

GUIMARÃES, I. G.; PEZZATO, L. E.; BARROS, M. M. Amino acid availability and protein digestibility of several protein sources for Nile tilapia, Oreochromis niloticus. Aquaculture Nutrition, Oxford, v. 14, n. 5, p. 396-404, 2008a.

GUIMARÃES, I. G.; PEZZATO, L. E.; BARROS, M. M.; TACHIBANA, L. Nutrient digestibility of cereal grain products and by-products in extruded diets for Nile tilapia. Journal of the World Aquaculture Society, Baton Rouge, v. 39, n. 6, p.781-789, 2008b.

HAULER, R. C.; CARTER, C. G. Reevaluation of the quantitative dietary lysine requirements of fish. Reviews in Fisheries Science, Philadelphia, v. 9, n. 3, p. 133-163, 2001.

JAUNCEY, K.; ROSS, B. A guide to tilapia feed and feeding. Scotland: University of Stirling, 1982.

JONES, J. D. Lysine-arginine antagonism in the chick. Journal of Nutrition, Bethesda, v. 84, n. 4, p. 313-321, 1964.

JONES, J. D.; PETERSBURG, S. J.; BURNETT, P. C. The mechanism of the lysine-arginine antagonism in the chick: effect of lysine on digestion, kidney arginase and liver transamidinase. Journal of Nutrition, Bethesda, v. 93, n. 1, p. 103-116, 1967.

KEEMBIYEHETTY, C. N.; GATLIN III, D. M. Dietary lysine requirement of juvenile hybrid striped bass (Morone chrysops x M. saxatilis). Aquaculture, Amsterdam, v. 104, n. 3-4, p. 271-277, 1992.

MARCOULI, P. A.; ALEXIS, M. N.; ANDRIOPOULOU, A.; ILIOPOULOU-GEORGUDAKI, J. Dietary lysine requirement of juvenile gilthead seabream Sparus aurata L. Aquaculture Nutrition, Oxford, v. 12, n. 1, p. 25-33, 2006.

MINISTÉRIO DA PESCA E AQUICULTURA - MPA. 
Boletim Estatístico da Pesca e Aquicultura Brasileira 2010. Ministério da Pesca e Aquicultura: Brasília, 2012.

MURTHY, H. S.; VARGHESE, T. J. Dietary requirement of juveniles of the indian major carp, Labeo rohita, for the essential amino acid lysine. The Israeli Journal of Aquaculture - Bamidgeh, Tel Aviv, v. 49, n. 1, p. 19-24, 1997.

NATIONAL RESEARCH COUNCIL - NRC. Nutrient requirements of fish and shrimp. Washington: National Academy Press, 2011.

. Nutrient requirements of warmwater fishesand shellfishes. Washington: National Academy Press, 1993.

PEZZATO, L. E.; MIRANDA, E. C.; BARROS, M. M.; FURUYA, W. M.; PINTO, L. G. Q.; PEZZATO, A. C. Digestibilidade aparente de ingredientes pela tilápia do Nilo (Oreochromis niloticus). Revista Brasileira de Zootecnia, Viçosa, MG, v. 31, n. 4, p. 1595-1604, 2002.

RODEHUTSCORD, M.; BORCHERT, F.; GREGUS, Z.; PACK, M.; PFEFFER, E. Availability and utilization of free lysine in rainbow trout (Oncorhynchus mykiss). 2. Comparison of L-lysine - $\mathrm{HCl}$ and L-lysine sulphate. Aquaculture, Amsterdam, v. 187, n. 1-2, p. 177-183, 2000.

SANTIAGO, C. B.; LOVELL, R. T. Amino acid requirements for growth of Nile tilapia. Journal of Nutrition, Bethesda, v. 118, n. 12, p. 1540-1546, 1988.
SAS INSTITUTE. SAS/STAT Use's guide. Release 6.03. 4. ed. Cary: SAS Institute NC, 1988.

SILVA, S. S.; QUEIROZ, S. Análises de alimentos: métodos químicos e biológicos. 2. ed. Imprensa Universitária: Viçosa, 2002.

SNETSINGER, D. C.; SCOTT, H. M. Efficacy of glycine and arginine in alleviating the stress induced by dietary excesses of single amino acids. Poultry Science, Champaing, v. 40, n. 6, p. 1675-1681, 1961.

TIBALDI, E.; LANARI, D. Optimal dietary lysine levels for growth and protein utilization fingerling sea bass (Dicentrarchus labrax L.) fed semipurified diets. Aquaculture, Amsterdam, v. 95, n. 3-4, p. 297-304, 1991.

WALTON, M. J.; COWEY, C. B.; ADRON, J. W. The effect of dietary lysine levels on growth and metabolism of rainbow trout (Salmo gairdneri). British Journal of Nutrition, Wallingford, v. 52, n. 1, p. 115-122, 1984.

WILSON, R. P. Amino acid requirements of fish. In: D'MELLO, J. P. F. (Ed.). Amino acids in farm animal nutrition. Wallingford: CAB International, 1994. p. 379389.

ZARATE, D. D.; LOVELL, R. T. Free lysine (L-lysine. $\mathrm{HCl}$ ) is utilized for growth less efficiently than proteinbound lysine (soybean meal) in practical diets by young channel catfish (Ictalurus punctatus). Aquaculture, Amsterdam, v. 159, n. 1-2, p. 87-100, 1997. 